\title{
Estimating the Value of a Depository Collection
}

\section{Elizabeth Psyck}

I $n$ the fall of 2018, I was asked to calculate the value of Grand Valley State University's (GVSU) general collection (defined as everything except Special Collections and University Archives) as part of risk mitigation planning and updating insurance coverage. Records indicated that our collection's value was last calculated 11 years earlier, and we lacked both written documentation and institutional memory regarding the process used to calculate that value. While there is a fairly significant body of knowledge around calculating the value of monographs, I struggled to find guidance on calculating the monetary value FDLP collections. There is a robust body of scholarship on promoting the intrinsic value of being a member of the FDLP to library administration and other stakeholders, but very few of them focus on detailed financial benefits of tangible collections.

\section{Existing Guidance}

FDLP guidance is very clear that depository collections "must be included in the insurance coverage for the library's collections." Since all depository libraries share this requirement, I decided to reach out to colleagues.

In October 2018, I sent a message to GOVDOC-L asking how other depositories had calculated their value. Unfortunately, the only advice I received was to review the list's archives for previous conversations on the topic. A search of the archives for the word "value" in the subject line returned 67 results, two of which were related to my email. The oldest relevant result was from March 8, 1999, when Mary Fetzer of Rutgers University, who faced the same challenges I did. ${ }^{2}$ She shared a summary of responses that included a method for calculating price per page, using the CIS price list for portions of the collection, and a reference to a $1980 \mathrm{DttP}$ article. ${ }^{3}$ A few months later, in September 1999, Julia F. Wallace announced that the Depository Library Council was taking up the issue in order to give the depository library community "some basic numbers." $\mathrm{On}$
January 25, 2001, Mary Redmond followed up with a rough draft of what would become "Resources on Costs of Replacing a Federal Document Depository Library Collection." ${ }^{5}$ Additional requests for information on how to calculate the monetary or replacement value of documents collections would be posted in October 2005, January 2009, January 2014, and August 2015. ${ }^{6}$ Of these later posts, only the one from January 2009 provides any information on a process for assigning value. Items were assigned generic prices ranging from $\$ 10$ for a map up to $\$ 50$ for a VHS tape or DVD. Undoubtedly, some posts are missing, particularly replies sent off list, but the consensus seemed to be that Redmond's "Resources on Costs of Replacing a Federal Depository Library Collection," from 2001, is the most up to date resource on calculating the value of a depository collection.

Needless to say, there have been significant changes in the Federal Depository Library Program since 2001, particularly in the number of types of documents available in physical formats. A modernized process would not only acknowledge the variety of formats and inflation, but also the relative difficulty in procuring replacement documents. Based on personal experience, not all documents distributed via the FDLP are available for purchase at the time of distribution, let alone several years later. We recently ran into this problem when a national park map loaned to another library was lost in transit. While there are commercial replacements and electronic versions available, we were not able to purchase a true replacement.

\section{Process and Limitations}

Since the depository collection was a small part of the overall collection I was working with, and there was a hard deadline, I had limited time to work on estimating the value of our government documents. I was not able to design and develop a fully new process, or collect a significant amount of new information, which would be required to update some of the methods 


\section{Psyck}

described in the literature. In order to identify the best course of action, I reviewed what collection data was easily available through our ILS.

GVSU's print documents collection is fully cataloged, which made identifying the number of titles quite simple. Additionally, since all of our government documents are housed in an Automated Storage and Retrieval System (ASRS), each individual item has an assigned barcode which allowed me to estimate the number of individual items with a fairly high level of accuracy. For a library that is not able to quickly pull these statistics from their ILS, one could estimate the number of items per linear foot for sections of the collection. These numbers may vary widely, as they do in general collections. For example, Bureau of Mines bound volumes will have fewer items per linear foot than maps from the National Park Service. I would recommend measuring items per linear foot in three areas: one that tends to have very small items, one with medium sized volumes, and one with larger bound volumes. Once you have a rough idea of how many items per linear foot there are for different SuDoc classes, you can estimate how many of your ranges have publications of different sizes and do some simple math. This would be a great project for student workers, who could take measurements and notes about item density while shelving.

Estimating the number of different types of materials (e.g., microfiche, media, monographs, serials, maps, etc.) will depend on how your library has organized your collection. At GVSU we had government document specific location codes for the general depository collection, maps, media, and microfiche. I was able to estimate the number of each type of item at the same time I ran queries to estimate the number of items overall. If your library uses the same location code, you may be able to use the item type or notes field to identify this information. If your items are interfiled with the rest of the collection and do not have a note, you can search GPO in the publisher field. Be aware that this is an imprecise method that will almost certainly return false positives and miss a significant number of items. When in doubt, talk with whomever manages library systems or is responsible the cataloging.

One thing I was not able to consider in my calculations was the age of an item. Due to ILS migrations, the earliest item creation date we have is June 21, 2008. Most of our physical collection was acquired before then. It is possible, in most cases, to pull publication year from the MARC record using field 264 \$c (or field 260 \$c for pre-RDA records), but variable formatting requires any data to be cleaned before it is used for analysis. For example, years may be displayed as follows: 1978, c1978, (C)1978, [1978], [1978?], <c1978>, etc. (This may not be the case with your collection.) There are three ways to handle the age of materials when calculating the value of a collection (NB: this is about a collection rather than an individual item), which method you choose will primarily depend on local policies and procedures. The first option is to ignore age and value all documents roughly the same. This is an inexact method that assigns the same value to a book regardless of if it is from 1890 and includes illustrated plates or if it is an annual report published last year. This method assumes that over an entire collection, the extremes will even out, producing an average value. The second option is to assume that documents depreciate and become less valuable as time passes. While this might undervalue some historic materials, it is a common formula in insurance and risk management, so you should check with whomever manages the library's insurance coverage to see if this is local practice. If it is, there will most likely be a formula that you can use (e.g., after 5 years an item has decreased in value by $50 \%$ ). Finally, you can assume that older materials are more valuable than newer ones, which would be the reverse of the second option.

Ultimately, I based the value of each item on the work done in 1999 by Michael Cotter of East Carolina University, updating the prices using the Bureau of Labor Statistics CPI Inflation Calculator. ${ }^{7}$ (See table 1.)

I did not adjust prices by age or perceived value of individual items, nor did I differentiate between items that are held in the general collection and those in Special Collections. (Depository items located in Special Collections at GVSU are predominantly items covered under shared housing agreements that require them to be stored in Special Collections.) In the original estimates, Cotter separated out CD-ROMs, National Archives film and other film. To update the formula, I collapsed that category into the more general "Media," which included CDs, VHS, DVDs, etc. The number of items in the depository collection was estimated by running lists in Sierra, using location codes to identify depository materials by type (e.g., WWG for electronic government documents, MIG for print documents

Table 1. Item Cost Estimate

\begin{tabular}{|l|l|l|}
\hline Format & Cotter's Estimate & Updated for Inflation \\
\hline Bound Documents & $\$ 13.00$ & $\$ 28.00$ \\
\hline Maps & $\$ 10.00$ & $\$ 15.00$ \\
\hline Fiche & $\$ 0.25$ & $\$ 0.50$ \\
\hline CD-Rom & $\$ 19.00$ & \\
\hline $\begin{array}{l}\text { National } \\
\text { Archives Film }\end{array}$ & $\$ 34.00$ & \\
\hline Other Film & $\$ 50.00$ & \\
\hline Media & & $\$ 30.00$ \\
\hline
\end{tabular}


in the ASRS at our Allendale campus, and STG is for items in the ASRS at our Grand Rapids campus). Using a basic Excel formula, I calculated the value of the collection based on the number of items and the updated table cost. Ultimately, our depository collection was estimated to be worth $\$ 1,131,682.50$.

\section{Alternatives}

Given the time constraints of this project and a relatively high tolerance for error, the method I chose was acceptable. If a more detailed or accurate estimate was needed, there are other ways to determine value. For recently received tangible items, searching the US Government Bookstore would help approximate replacement costs for items that are available for sale. For items that are no longer available for sale, an estimate of per item cost, based on similar items, could be made. For parts of the collection that are particularly important, replacement costs could be estimated by searching for the same (or similar) items on used book sellers' websites. For example, as of December 19, 2019, Bureau of Mines Bulletin 156, Petroleum Technology No. 44 from 1918 is available for $\$ 10$, plus $\$ 3.99$ shipping from Alibris. For items that are available as reprints, digitized collections, or from vendors, estimated value or replacement cost can be calculated using information provided by the vendors. For example, price quotes from Bernan, ProQuest, or HeinOnline would help to estimate replacement cost for access, if not the physical objects themselves.

You may work in a library that has an established process for estimating value or replacement cost, in which case you could modify that process. While government publications are a unique collection, they share certain attributes with special collections and archives as well as general collections. Like archival collections, some depository items may be irreplaceable or prohibitively expensive to replace, alternately, they may be unexpectedly inexpensive. Like general collections, items may be available to repurchase, either as a new copy or as a reasonably priced used book. By blending already existing processes, you can develop documentation specifically for government publications.

\section{Conclusion}

When I started this project, I struggled to find any sort of explicit guidance on how to calculate the monetary value of a depository collection. How do you put a price on something you do not, and sometimes can not, purchase? The method I settled on was good enough for my institution's needs, but I am confident that there are more accurate, alternative ways to make the same calculations. Ultimately, my goal in publishing this article is to provide the resource I was looking for and I hope that by sharing my experience, other libraries will come forward and the depository community can work collaboratively to create a stronger, more robust, valuation process.

For information regarding estimating the value of general library collections, I recommend the following ACRL SPEC Kit: Martin, Susan K., and Association of Research Libraries. Insuring and Valuing Research Library Collections: A SPEC Kit. Washington, DC: Association of Research Libraries, Office of Leadership and Management Services, 2002. http://hdl.handle .net/2027/mdp.39015052311175.

Elizabeth Psyck (psycke@gvsu.edu), Government and Open Collections Librarian, Grand Valley State University

\section{Notes}

1. Karen Sieger, "Physical Facilities and Collection Maintenance," https://www.fdlp.gov/requirements-guidance /guidance/22-physical-facilities.

2. Mary Fetzer, "Assessing Value of Documents Collections," GOVDOC-L Archives, March 8, 1999, http:// gvsu.edu/s/1nv.

3. Sandra K. Faull, "Cost and Benefits of Federal Depository Status for Academic Research Libraries," DttP: Documents to the People 8, no. 1 (January 1980): 33-39.

4. Julia F. Wallace, "Cost and Value of Documents Collections," GOVDOC-L Archives, September 4, 1999, http://gvsu.edu/s/1ns

5. Mary Redmond, "Re: Depository Collection Value," GOVDOC-L Archive, January 25, 2001, http://gvsu.edu /s/1np; Redmond, Mary. "Resources on Costs of Replacing A Federal Document Depository Library Collection," Administrative Notes: Newsletter of the Federal Depository Library Program 22, no. 16 (November 15, 2001): 4-6, http://gvsu.edu/s/1nq.

6. Linda Johnson, "Value of Collection \& Insurance," GOVDOC-L Archives, October 6, 2005, http://gvsu.edu/s/1no; Andrea Craley, "Question on How to Assign Monetary Value to FDLP Collections," GOVDOC-L Archives, January 8, 2009, http://gvsu.edu/s/1nu; Suzanne Caro, "REFQ: Replacement Value," GOVDOC-L Archives, January 16, 2014, http://gvsu.edu/s/1nt; Helen Murtagh Sheehy, "Value of Depository Collections," GOVDOC-L Archives, August 19, 2015, http://gvsu.edu/s/1nr.

7. Redmond, "Resources on Costs of Replacing A Federal Document Depository Library Collection.” 